\title{
Synthesis and Properties of Poly(urethane-urea-imide) Block Copolymers
}

\author{
Hasan A. Al-SALAH \\ Polymer Science and Technology Research Loboratory, \\ Department of Chemistry, Mu'tah University, \\ Mu'tah, Jordan
}

(Received April 11, 1990)

\begin{abstract}
Poly(urethane-urea-imide) (PUUI) block copolymers were prepared from different types of amine-terminated polyurethane oligomers with benzophenonetetracarboxylic dianhydride. PUUIs consisted of two types of segments, the soft segments with the repeating unit of poly(tetramethyleneoxide) (PTMO) and the hard segments composed of urethane, urea, and imide groups. Characterization of PUUIs was carried out by IR spectroscopy, solution viscosity, thermal analysis, and stress-strain properties. It was found that these block copolymers have considerable better thermal stability and tensile properties than typical linear polyurethanes (PU).

KEY WORDS Amine-Terminated Polyurethane Oligomer / NCO-Terminated Prepolymer / Soft Segment / Hard Segment / Young's Modulus / Maximum Decomposition Temperatures /
\end{abstract}

The reaction between diisocyanates and a mixture of diols of different molecular weights provides thermoplastic polyurethane (PU) elastomers, with a block segment structure. The preparation of thermoplastic PU elastomers with a wide range of properties can be carried out by changing the combining various ratios of reactive intermediates with a variations in molecular structure. The properties of these polymers appear to result from a combination of chain segment flexibility, the rigidity of aromatic units, chain entanglement, orientation of segments, hydrogen bonding, and other intermolecular interactions. ${ }^{1-9}$

Typical PU copolymers are known to exhibit small resistance to heat. This low heat resistance is the main reason of relatively limited technical applicability of these polymers. One of the reported methods to improve the thermal stability of these polymers is a chemical modification of their structure by heterocyclic groups; e.g., isocyanurate,,$^{10,11}$ oxazolidone, and imide groups. ${ }^{12-16}$
In the present work, poly(urethane-ureaimide) (PUUI) block copolymers were prepared by reacting benzophenonetetracarboxylic dianhydride (BTDA) with amine-terminated polyurethane oligomers. Preliminary studies, describing the synthesis, characterization, theremal behavior, and stress-strain properties of PUUIs, forms the basis of the present paper. The viscoelastic properties and morphology of these copolymers will be reported in another publications.

\section{EXPERIMENTAL}

\section{Materials}

Poly(tetramethylene oxide) (PTMO, E. I. Du Pont De Nemours Co.) of 1000 molecular weight was dehydrated under vacuum at $70^{\circ} \mathrm{C}$ for $10 \mathrm{~h}$. 3,3',4,4'-Benzophenonetetracarboxylic dianhydride (BTDA, Fluka), 4,4'-oxydianiline, 4,4'-methylenedianiline (MDA, Merck), and 1,4-phenylenediamine (PDA, Merck) were obtained commercially and vacuum sublimed 


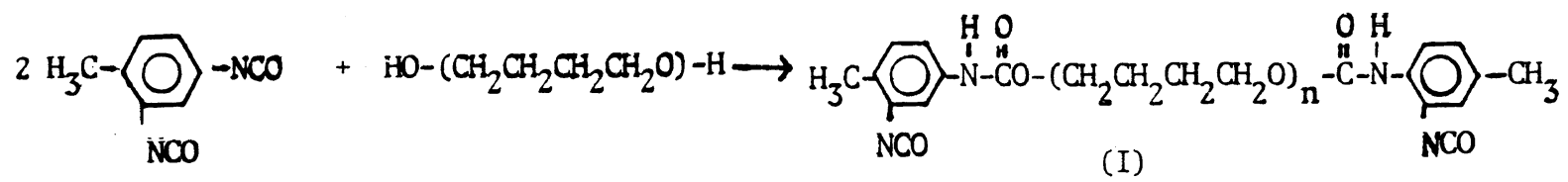

NCO-Terminated PU

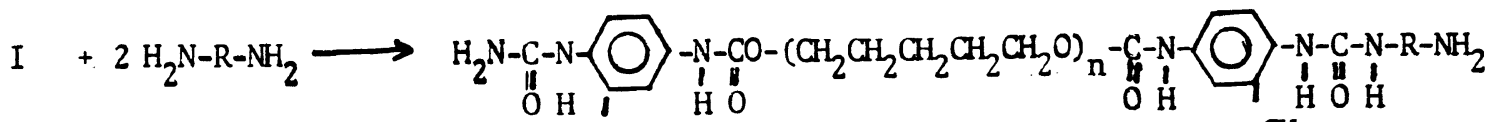

$\mathrm{H}_{2} \mathrm{~N}$

(II)

- Urea

APU-01igomer

mun Urethane

(a)
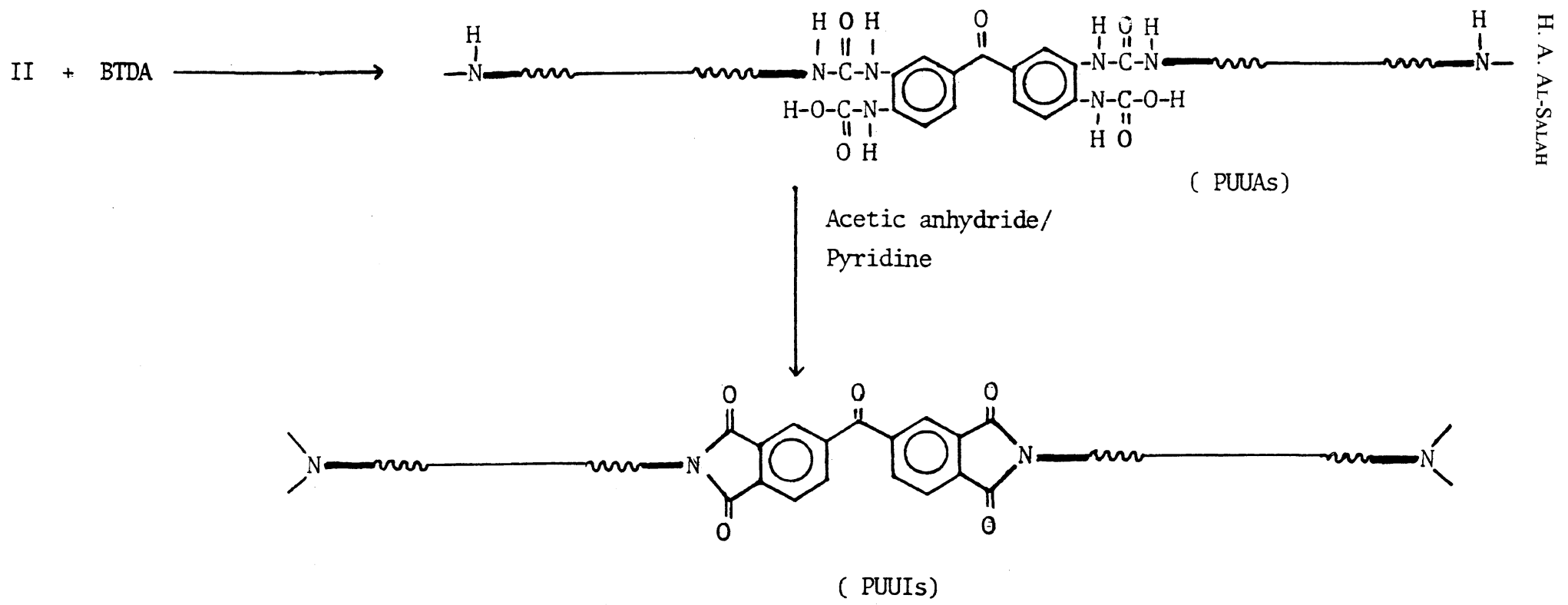

Figure 1. Synthetic scheme for PUUI block copolymers. 
to yield off white solid. 1,6-Hexanediamine (HDA, Prolabo), 1,12-dodecanediamine (DDA, Merck), and $N, N$-dimethylformamide (DMF, Fluka) were fractionally distilled under vacuum. Tolylene diisocyanate (TDI, Merck) utilized a mixture of the 2,4- and 2,6-isomers of 80 and $20 \%$, respectively, was used as received.

\section{Synthesis of Amine-Terminated Polyurethane} Oligomers (APU)

NCO-terminated polyurethane prepolymer at $6.34 \%$ NCO determined by di- $n$-butylamine titration method ${ }^{17}$ was prepared by reacting two equivalents of TDI with one equivalent of PTMO. One equivalent of NCO-terminated PU prepolymer was dissolved in anhydrous DMF, produced $50-60 \%$ solids $(\mathrm{w} / \mathrm{w})$ was added two equivalents of a diamine solution at $0^{\circ} \mathrm{C}$. The reaction was continued for $1 \mathrm{~h}$ at $0^{\circ} \mathrm{C}$ and at room temperature until theoretical amine content (detemined by nonaqueous titrimetry ${ }^{18}$ ) was reached. The reactions were performed under a continuous flow of dry nitrogen.

\section{Synthesis of Poly(urethane-urea-imide) Block Copolymers (PUUIs)}

Polymerization was carried out at a concentration of $10-15 \%$ solids $(w / w)$ by slow addition of stoichiometric amount of BTDA solution to a mechanically stirred solution of the APU under a continuous flow of nitrogen at $10^{\circ} \mathrm{C}$. The reaction was continued for $15 \mathrm{~h}$ at ambient temperature. The copolymer solution of poly(urethane-urea-amic acid) (PUUA) was imidized by addition of an equimolar mixture of pyridine and acetic anhydride at $70^{\circ} \mathrm{C}$ for $8 \mathrm{~h}$ to afford the corresponding PUUIs. The reduced viscosity of PUUAs and PUUIs in DMF listed in Table I ranged from 0.63 to 0.92 for PUUAs and 0.67 to $1.22 \mathrm{dl} \mathrm{g}^{-1}$ for PUUIs, measured at a concentration of $0.5 \mathrm{dlg}^{-1}$ at $30^{\circ} \mathrm{C}$.

The sample films used for characterization were made by solution casting of 6 to 8 weight
Table I. Composition and reduced viscosity of PUUA and PUUI block copolymers ${ }^{\mathrm{a}}$

\begin{tabular}{cccc} 
& & \multicolumn{2}{c}{ Reduced viscosity $^{\mathrm{b}} / \mathrm{dl} \mathrm{g}^{-1}$} \\
\cline { 3 - 4 } PUUI & Diamine & PUUA & PUUI \\
\hline A & PDA & 0.63 & 0.67 \\
B & MDA & 0.63 & 0.75 \\
C & ODA & 0.78 & 1.01 \\
D & HDA & 0.89 & 1.17 \\
E & DDA & 0.92 & 1.22 \\
\hline
\end{tabular}

a PUUIs composed of TDI/PTMO/Diamine/BTDA at $2 / 1 / 2 / 1$ equivalent ratios.

b Measured in DMF $\left(c=0.5 \mathrm{gdl}^{-1}\right)$ at $30^{\circ} \mathrm{C}$.

c PDA, 1,4-phenylenediamine; MDA, 4,4'-methylenedianiline; ODA, 4,4'-oxydianiline; HDA, 1,6-hexanediamine; DDA, 1,12-dodecanediamine.

percent of PUUI solutions in DMF on an aluminum molds coated with teflon and the solvent was evaporated in circulated air oven at $80^{\circ} \mathrm{C}$ and further dried under vacuum at $80^{\circ} \mathrm{C}$ for $24 \mathrm{~h}$, giving transparent, tough plastic films with microphase-separated morphology.

\section{Characterization}

The reduced viscosity of PUUAs and PUUIs were measured with $0.5 \%$ solution in DMF at $30^{\circ} \mathrm{C}$ using Ubbelhode viscometer. Infrared (IR) spectra were recorded on a Pye-Unicam IR-spectrophotometer with $\mathrm{KBr}$ plates. Differential scanning calorimetry (DSC), thermogravimetry (TG), and derivative thermogravimetry (DTG) were performed on a Du Pont Thermal Analyzer 2000 system in a combination with a standard 910 DSC cell and TG-951. Measurements were carried out at a heating rate of $20^{\circ} \mathrm{C} \mathrm{min}^{-1}$ in atmosphere of dry nitrogen at a flow rate of $75 \mathrm{~cm}^{3} \mathrm{~min}^{-1}$ and a sample size was $13 \pm 2 \mathrm{mg}$. The stress-strain experiments were obtained using a table model Instron tensile testing machine at room temperature. The crosshead speed of $5 \mathrm{~cm} \mathrm{~min}^{-1}$ and a gauge length of $3.25 \mathrm{~cm}$. The samples were cut with an ASTM 412 Die. 


\section{RESULTS AND DISCUSSION}

The new block copolymers of PUUIs used in this study were synthesized by a stepcondensation reaction ${ }^{19}$ outlined in Figure 1. The IR spectra of PUUI copolymers are characterized by strong absorption at 3310 and $1540 \mathrm{~cm}^{-1}$ for the hydrogen bonded $\mathrm{NH}$ group, $1720 \mathrm{~cm}^{-1}$ for nonbonded urethane carbonyl, $1640 \mathrm{~cm}^{-1}$ for hydrogen bonded urea, $1780 \mathrm{~cm}^{-1}$ for the imide ring. Since the $\mathrm{NH}$ group is mostly hydrogen bonded while the carbonyl group is not in the IR spectra (Figure 2) confirms that the NH groups are bonded to other hydrogen bonded acceptors in the samples, presumably the ether groups of soft segment (PTMO) and imide carbonyl groups. A large amount of hydrogen bonding between the urethane, urea, imide, and ether groups is suggesting of a dispersion of hard soft segments in a soft segment matrix.

\section{Thermal Analysis}

Typical DSC curves of PUUI samples are shown in Figure 3, and thermal transition data for these samples are summarized in Table II. For each sample was heated at $20^{\circ} \mathrm{C} \mathrm{min}^{-1}$ up to $200^{\circ} \mathrm{C}$ and then quench cooled and heated again. The soft segment $T_{\mathrm{g}}$ is $-78^{\circ} \mathrm{C}$ from quenched PTMO and the $T_{\mathrm{g}}$ of PUUI samples ranged from -29 to $-10^{\circ} \mathrm{C}$ which is higher than that of pure PTMO. This behavior presumably due to a cartain degree of soft and hard segments mixing. The soft and hard segments mixing can be explained according to the molecular structure of PUUI samples which are prepared from TDI isomers. The TDI isomers contains a high proportion of the asymmetrical isomer, 2,4-TDI which can result in head to tail isomerization within the PUUI structure. The amorphous character of the hard segments containing the isomeric TDI units may result in considerable intermixing of the hard segments with soft segments. The intermixing can produce restrictions on the relative mobility of the PTMO units and

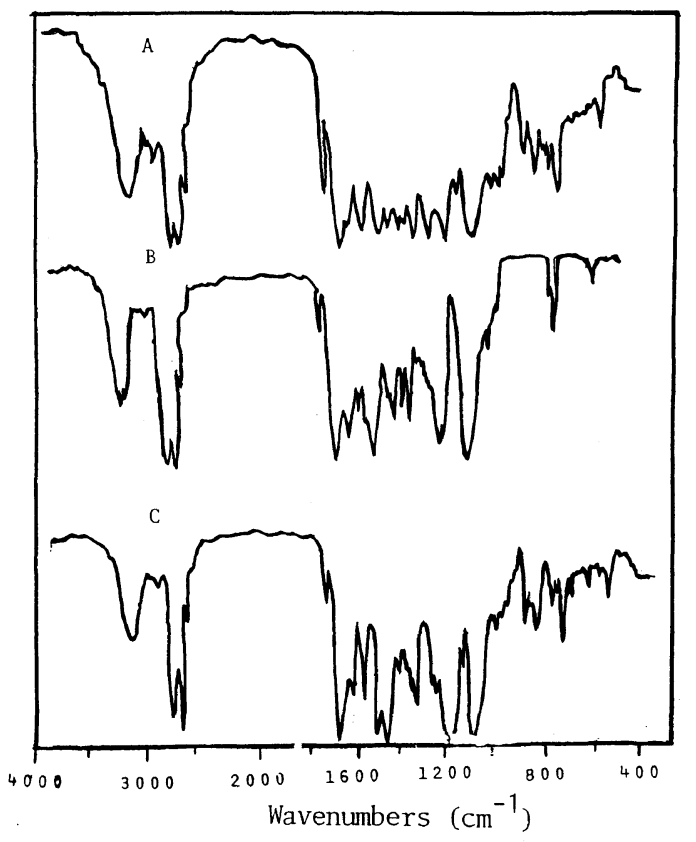

Figure 2. Infrared spectrum of PUUI samples. A, B, and C: see Table I.

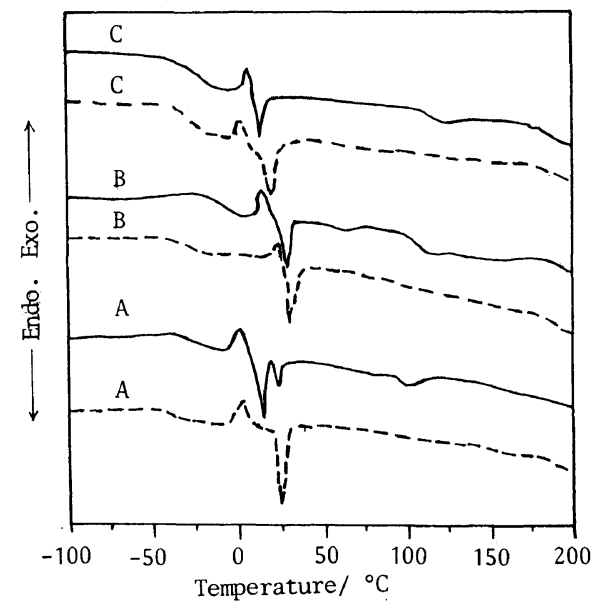

Figure 3. Typical DSC curves for PUUI samples: (-), first heating; (---), second heating. A, B, and C: see Table I.

increase the $T_{\mathrm{g}}$ of the PUUI samples. ${ }^{20-22}$ The PTMO melting endotherms at about $16^{\circ} \mathrm{C}$ suggests that soft segment crystallize which arise from the high polarity of urea and imide groups. The aromatic diamine-based samples possess a soft segment $T_{\mathrm{g}}$ that is always lower than that of aliphatic diamine derived sam- 
Synthesis and Properties of PUUI Block Copolymers

Table II. Differential scanning calorimetry data

\begin{tabular}{|c|c|c|c|c|c|c|}
\hline & \multirow[t]{2}{*}{ PUUIs } & \multicolumn{3}{|c|}{$\begin{array}{l}\text { Glass transition temp } \\
\qquad T_{\mathrm{g}} /{ }^{\circ} \mathrm{C}\end{array}$} & \multirow{2}{*}{$\begin{array}{l}\text { Crystallization } \\
\text { peak } /{ }^{\circ} \mathrm{C}\end{array}$} & \multirow{2}{*}{$\begin{array}{c}\text { Crystalline melting } \\
\text { peak } /{ }^{\circ} \mathrm{C}\end{array}$} \\
\hline & & Onset & Midpoint & Endpoint & & \\
\hline \multirow[t]{2}{*}{ A } & First heating & -52 & -29 & -3 & 0 & 15 \\
\hline & Second heating & -55 & -32 & -5 & -2 & 15 \\
\hline \multirow[t]{2}{*}{ B } & First heating & -43 & -27 & -5 & 2 & 18 \\
\hline & Second heating & -45 & -29 & -7 & 0 & 18 \\
\hline \multirow[t]{2}{*}{$\mathrm{C}$} & First heating & -31 & -25 & -6 & 4 & 16 \\
\hline & Second heating & -35 & -25 & -8 & 2 & 18 \\
\hline \multirow[t]{2}{*}{$\mathrm{D}$} & First heating & -25 & -12 & -4 & 12 & 27 \\
\hline & Second heating & -28 & -14 & -6 & 10 & 28 \\
\hline \multirow[t]{2}{*}{$\mathrm{E}$} & First heating & -22 & -10 & -5 & 12 & 28 \\
\hline & Second heating & -25 & -12 & -7 & 12 & 28 \\
\hline
\end{tabular}

Table III. TG and DTG results for PUUI block copolymers

\begin{tabular}{|c|c|c|c|c|c|c|}
\hline \multirow{3}{*}{ PUUI } & \multirow{2}{*}{\multicolumn{2}{|c|}{ 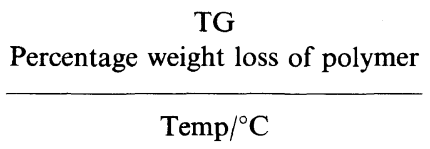 }} & \multicolumn{4}{|c|}{$\begin{array}{c}\text { DTG } \\
\text { Decomposition temp } /{ }^{\circ} \mathrm{C}\end{array}$} \\
\hline & & & \multicolumn{2}{|c|}{ First stage } & \multicolumn{2}{|c|}{ Second stage } \\
\hline & 300 & 500 & Initial & Maximum & Initial & Maximum \\
\hline A & 4.2 & 60.1 & 282 & 348 & 402 & 462 \\
\hline B & 5.1 & 63.1 & 276 & 340 & 397 & 445 \\
\hline $\mathrm{C}$ & 6.9 & 65.6 & 270 & 325 & 390 & 437 \\
\hline D & 7.9 & 81.7 & 260 & 307 & 380 & 422 \\
\hline $\mathrm{E}$ & 7.2 & 85.3 & 265 & 312 & 385 & 428 \\
\hline$F^{a}$ & 31.3 & 82.7 & 185 & 290 & 375 & 392 \\
\hline
\end{tabular}

a $\mathrm{F}=$ polyurethane prepared from TDI/PTMO/1,4-butanediol at 2/1/1 equivalent ratios.

ples. Such an effect can be considered as a consequence of the rigidity of aromatic diamines which enhances the hard segment ordering and lower the molecular mobility of the soft segment. The order of decreasing of $T_{\mathrm{g}}$ follows the rigidity of a diamine. Table II also shows that the soft segment $T_{\mathrm{g}}$ depends on the aliphatic diamine molecular weight. Such an effect can also be considered as a consequence of molecular mobility since increasing the aliphatic diamine molecular weight increases the length of the flexible sequences and increases the $T_{\mathrm{g}}$ as a result of intermixing between hard and soft segments.

TG and DTG curves for all PUUI samples show more or less similar pattern. Typical TG

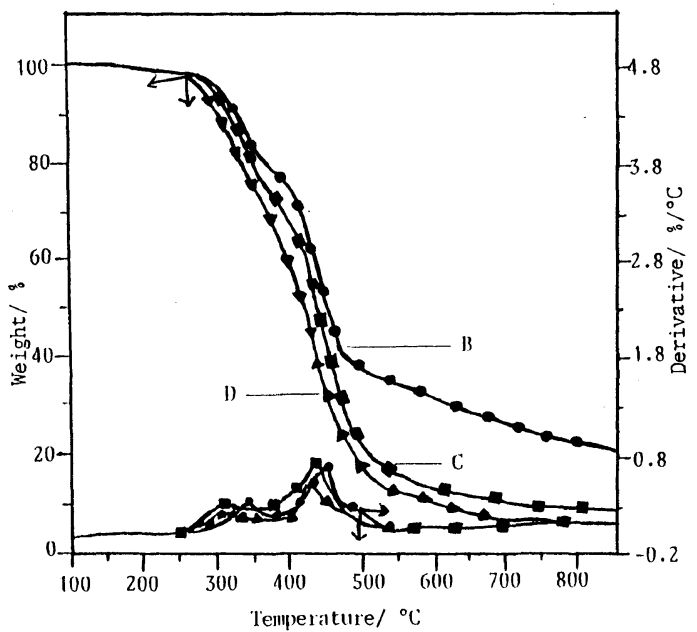

Figure 4. Typical TG and DTG curves for PUUI samples. B, C, and D: see Table I. 


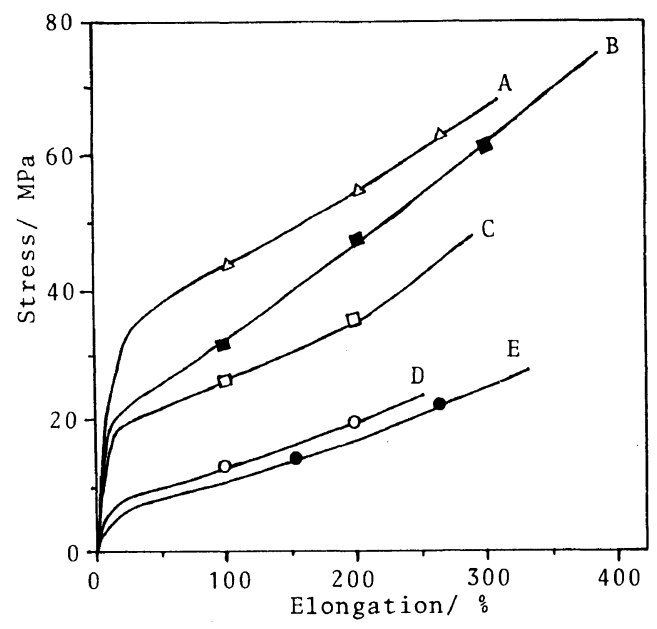

Figure 5. Stress-strain curves for PUUI samples. A, B, C, D, and E: see Table I.

Table IV. Tensile properties for PUUI block copolymers ${ }^{\mathrm{a}}$

\begin{tabular}{|c|c|c|c|c|c|}
\hline \multirow{2}{*}{ PUUI } & $T_{\mathrm{s}}$ & $E$ & $E_{\mathrm{y}}$ & $M_{100}$ & $M_{200}$ \\
\hline & $\mathrm{MPa}$ & $\%$ & $\mathrm{MPa}$ & $\mathrm{MPa}$ & $\mathrm{MPa}$ \\
\hline A & 68 & 312 & 157 & 43 & 54 \\
\hline B & 76 & 388 & 126 & 31 & 47 \\
\hline $\mathrm{C}$ & 48 & 292 & 72 & 26 & 35 \\
\hline D & 24 & 256 & 35 & 13 & 19 \\
\hline $\mathrm{E}$ & 29 & 330 & 31 & 11 & 17 \\
\hline
\end{tabular}

a $T_{s}=$ ultimate tensile strength; $E=$ elongation at break; $E_{\mathrm{y}}=$ Young's modulus; $M_{100}=$ modulus at $100 \%$ elongation; $M_{200}=$ modulus at $200 \%$ elongation.

and DTG-curves of PUUI samples are given in Figure 4. The DTG curves indicate two main reaction stages occur during the degradation. The first reaction stage appears around $260^{\circ} \mathrm{C}$ and the second stage at around $390^{\circ} \mathrm{C}$. Loss in weight of the polymer at different temperatures and the maximum decomposition temperatures were represented in Table III and determined from the respective TG and DTG, respectively. The results showed that the thermal stability of polyurethane was improved by incorporation of imide groups and the aromatic diamine-based PUUIs are more thermally stable than the aliphatic diamine-derived samples.

\section{Stress-Strain Properties}

Mechanical properties as determined by stress-strain analysis are shown in Figure 5, and the results are summarized in Table IV. The aromatic diamines-based PUUI samples have higher Young's modulus and ultimate tensile strength than the PUUI samples derived from aliphatic diamines. The Young's modulus increase is due to the greater rigidity imposed by the aromatic diamines.

Acknowledgments. The author is deeply indepted to Mu'tah University for financial support to enable me to carry out this work.

\section{REFERENCES}

1. J. T. Koberstein and T. P. Russel, Macromolecules, 19, 714 (1986).

2. J. H. Saunders, J. A. Burronghs, and L. P. Williams, J. Appl. Polym. Sci., 19, 1387 (1975).

3. T. Yokoyama and M Furukawa, "International Progress in Urethane," Vol. 2, Technomic, Westport, Conn., 1976, p 125.

4. C. B. Wang and S. L. Cooper, Macromolecules, 16, 775 (1983).

5. J. W. C. Van Bogart, D. A. Bluenke, and S. L. Cooper, Polymer, 22, 1428 (1981).

6. G. L. Wilkes and S. Abouzahr, Macromolecules, 14, 456 (1981).

7. K. C. Frisch and S. L. Reegan, "Advances in Urethane Science and Technology,” Vol. 3, Technomic, Westport, Conn., 1977, p 191.

8. K. C. Frisch and S. Wong, "Advances in Urethane Science and Technology," Vol. 8, Technomic, Westport, Conn., 1981, p 75.

9. H. A. Al-Salah, K. C. Frisch, H. X. Xiao, and J. A. McLean, J. Polym. Sci., Polym. Chem. Ed., 26, 1609 (1988).

10. C. L. Wang, D. Klempner, and K. C. Frisch, J. Appl. Polym. Sci., 30, 4337 (1985).

11. I. Bechara, J. Cell. Plast., 15, 102 (1979).

12. D. Brown and J. Weinert, Angew. Mocromol. Chem., 79, 1 (1979).

13. S. Isoda, H. Shimada, M. Kochi, and H. Kambe, $J$. Polym. Sci., Polym. Phys. Ed., 19, 1293 (1981).

14. C. Arnold, J. Polym. Sci., Macromol. Rev., 14, 322 (1979).

15. J. Fontan and J. de Abajo, Polimery (Warsaw), 11, 511 (1975).

16. B. Masiulanis and R. Zielenski, J. Appl. Polym. Sci., 30, 2731 (1985).

17. D. J. David and H. B. Staley, "Analytical 
Chemistry of Polyurethane," Vol. XVI, Part III, Wiley-Interscience, New York, N. Y., 1969, pp. 357-359.

18. N. Yui, K. Nojima, K. Sanui, and N. Ogata, Polym. J., 17, 969 (1985).

19. J. H. Saunders and K. C. Frisch," Polyurethanes, Chemistry and Technology," Part 1, Interscience,
New York, N. Y., 1962.

20. B. Fu and W. J. MacKnight, Rubber Chem. Technol., 59, 896 (1986).

21. J. W. C. Van Bogart, D. A. Bluemke, and S. L. Cooper, Macromolecules, 16, 848 (1983).

22. C. B. Wang and S. L. Cooper, Macromolecules, 16, 775 (1983). 